7. Reprod. Fert. (1970) 23, 435-440

\title{
THE EFFECT OF THE PRESENCE OF A BOAR ON THE ATTAINMENT OF PUBERTY IN GILTS
}

\author{
P. H. BROOKS AND D. J. A. GOLE \\ University of Nottingham School of Agriculture, \\ Sutton Bonington, Loughborough, Leicestershire \\ (Received 5th Fanuary 1970, revised 8th Fune 1970)
}

\begin{abstract}
Summary. Groups of gilts of similar age, weight and breeding were allocated at 165 days of age to four treatments. One group of gilts was isolated from boars throughout the experiment. Fewer animals reached puberty during the experiment in this group than in the other groups where boars were introduced. Introduction of a boar to gilts at 165 or 190 days of age resulted in precipitation of oestrous activity. At 165 days, considerable synchrony of oestrus was obtained when there was a rotation of the boars used for testing, but the effect was much less marked when only one boar was used.
\end{abstract}

\section{INTRODUCTION}

Various estimates have been made of the age at which gilts reach puberty and the factors that modify the age at puberty. These have been reviewed by Tassell (1967). While mean values obtained by different authors are in general agreement, pubertal ages as low as 136 days have been recorded in some cases (Sumption, Rempel \& Winters, 1961). The sample variance in most estimates would suggest that factors other than weight or age determined the attainment of puberty.

It has been suggested (Brooks \& Cole, 1969) that, in the pig, puberty may be hastened by the introduction of a male, but that if the male is introduced too early in the prepubertal period, instead of hastening puberty it may result in a delay. Reed (1967) has shown that some gilts, though of a weight and age conducive to the attainment of puberty, did not attain this state while housed in isolation from the male. Thibault, Gourot, Martinet, Mauléon, du Mesnil du Buisson, Ortavant, Pelletier \& Signoret (1966) have concluded that stress imposed by transportation of gilts of pubertal age is a stronger stimulus to cyclic behaviour than introduction of the male.

The experiment reported here was undertaken in order to study the effect of the presence of the male on pubertal age of the gilt, and to investigate ways in which this effect might be modified.

\section{MATERIALS AND METHODS}

The experiment was designed to start when the average age of the animals was 165 days and terminate when their average age was 220 days. 


\section{Animals and housing}

Forty Landrace $\times$ (Landrace $\times$ Large White) gilts and eight Landrace $\times$ Large White gilts were used. The gilts were arranged in twelve randomized blocks. As far as possible, each block was made up of four litter-sisters. Animals within each block were randomly allocated to the four treatments.

The seven males were Landrace $\times$ (Landrace $\times$ Large White) vasectomized males.

The twelve animals on each treatment were group-housed in deep strawed yards and fed individually, once daily with $4 \mathrm{lb}$ of breeding-sow nuts, the composition of which is shown in Table 1 .

\section{TABLE 1}

\section{GOMPOSITION AND GALCULATED ANALYSIS OF THE DIET}

\begin{tabular}{lr}
\hline Composition (\%) & \\
Ground barley & 50 \\
Ground wheat & 40 \\
White fishmeal & 5 \\
Soyabean meal & 5 \\
Plus $1.0 \%$ of a mineral/vitamin supplement * \\
Calculated analysis of air-dry feed \\
Digestible energy value (kcal/kg) \\
Grude protein (\%) \\
Ga $(\%)$ & 3186 \\
P $(\%)$ & $15 \cdot 6$ \\
& $0 \cdot 6$ \\
\end{tabular}

* Supplement provides $/ \mathrm{kg}$ diet: $\mathrm{Ca}, 1.9 \mathrm{~g}$; $\mathrm{P}, 1.0 \mathrm{~g} ; \mathrm{NaCl}, 2.5 \mathrm{~g} ; \mathrm{Fe}, 60 \mathrm{mg} ; \mathrm{Zn}, 50 \mathrm{mg}$; vitamin A, 6000 i.u.; vitamin $D, 250$ i.u.; riboflavine, $2.5 \mathrm{mg}$; nicotinic acid, $10 \mathrm{mg}$; pantothenic acid, $2.5 \mathrm{mg}$; vitamin $\mathrm{B}_{12}, 10 \mu \mathrm{g}$; vitamin $\mathrm{E}, 10 \mathrm{mg}$.

Water was freely available from automatic drinking bowls. Each group was separated from contact with other animals in the experiment by yards containing mature gestating sows. The animals were kept in strict isolation from all males other than those specified.

The vasectomized boars were housed in huts with outside runs, situated as far from the experimental gilts as possible.

\section{Treatments}

After introduction to the yards, the gilts were allowed 1 day to acclimatize before the experimental treatments were imposed.

In order to study the relationship between the introduction of the male and the attainment of puberty in gilts, four treatments were applied in which boars were introduced to groups of gilts on two treatments at 165 days of age, and one treatment at 190 days of age. A further treatment involved keeping gilts isolated from the boars throughout the experiment. The two treatments involved the introduction of the boar at 165 days; in one case, the same boar was used throughout and in the other four, boars were used in rotation.

Group A, 'no-boar group'. This group was kept in isolation from boars throughout the experimental period. 
Group $B$, 'one-boar group'. One boar was introduced to this group at 165 days. Previous observations at this centre (Brooks \& Cole, 1969) suggested that prolonged association with the same male in the prepubertal period delayed sexual maturity, possibly due to the females becoming habituated to the male. In an attempt to repeat this effect, the gilts in Group B were tested for heat with the same boar throughout the experiment.

Group $C$, 'changing-boar group'. The animals in this group were also exposed to males from 165 days of age. In order to remove the possibility of habituation and induce puberty as early as possible, the gilts in Group $\mathbf{G}$ were subjected to a routine in which they were tested with different males on alternate weeks. Two pairs of litter-brother vasectomized boars were used, the two boars of the pair being used simultaneously. During the first 4 days of the experiment, two other boars were used but proved unsuitable due to their size.

Group $D$, '190-day group'. Observations within this herd have shown the mean age at puberty to be approximately 190 days. The gilts in this group were isolated from contact with boars until they averaged 190 days of age. From 190 to 220 days, they were tested with the same pair of litter-brother vasectomized boars. It was hoped that by introducing the boar at an age which was, in our experience, conducive to the attainment of puberty, a precipitation of cycle activity would result.

\section{Oestrus testing}

Testing for oestrus was conducted in two ways, either:

(a) in the absence of a boar, gilts were observed daily and were considered to be on heat when they gave a positive response to the 'riding test' (Reed, 1967). Note was made of any gilts which showed vulval swelling or reddening but gave a negative response to the riding test; or

(b) in the presence of a boar, gilts were observed daily and were considered to be on heat when they permitted intromission by the vasectomized boars.

A testing period of approximately $30 \mathrm{~min} /$ group was allowed after feeding in the morning and the boars were then returned to their own accommodation.

\section{RESULTS}

The mean age of the gilts at the start of the experiment was 163 days, and their mean weight was $155 \mathrm{lb}$.

The pattern of puberty occurrence is shown in Text-fig. 1. Only seven of the twelve animals isolated from the boar (Group A) reached puberty during the experimental period. These gilts had a mean pubertal age of 209 days and a mean weight of $199 \mathrm{lb}$.

A higher percentage of gilts reached puberty in the groups which had experienced contact with the male, and the gilts were also younger at puberty.

Different patterns of pubescence were obtained in the two treatments in which the boar was first introduced at 165 days. All the gilts in Group $\mathbf{C}$ reached puberty during the experimental period, with eleven of the twelve animals reaching puberty over a period of 3 days. The mean pubertal age of the 
animals in this group was 172.4 days with a range of 167 to 183 days; their mean pubertal weight was $163 \cdot 2 \mathrm{lb}$.

In Group B, in which the same boar was used from 165 to 220 days, five gilts reached puberty in the 14 days following the introduction of the boar and, thereafter, the pattern of puberty occurrence was protracted, with only nine gilts reaching puberty during the experimental period.

The animals in Group D were isolated from the boar until 190 days of age. Between 165 and 190 days, only one gilt reached puberty. Following the introduction of a male, however, a number of gilts reached puberty, the pattern of puberty attainment being similar to that in Group G.

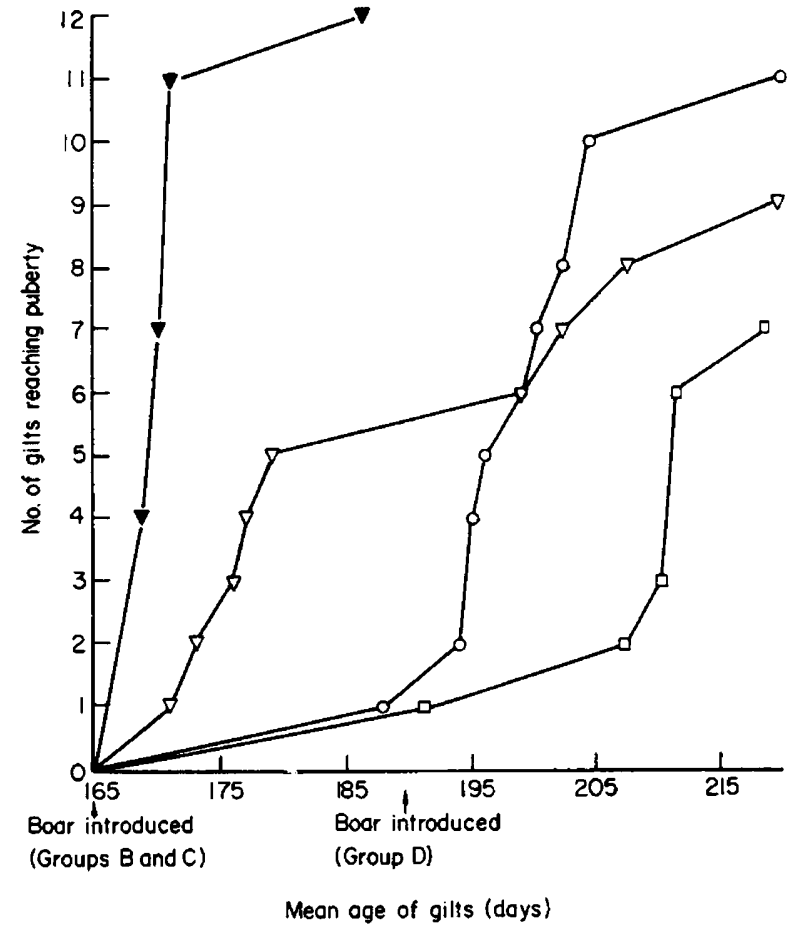

Text-Fic. 1. Pattern of puberty attainment. $\square$, Group A; $\nabla$, Group B; $\mathbf{\nabla}$, Group C; O, Group D.

Two casualty pigs were removed from the experiment. In Group A, one gilt was removed suffering from meningitis and in Group B, one gilt was slaughtered due to lameness.

All the animals which attained puberty during the experimental period maintained normal cyclic behaviour and were subsequently mated.

Of those animals failing to reach puberty during the experiment, all but two reached puberty by 250 days of age. The two animals failing to reach puberty were slaughtered at that time and were found to have infantile reproductive tracts.

\section{DISGUSSION}

The results of this experiment demonstrate that the pattern of puberty attain- 
ment and the age at which gilts attain puberty is modified by factors associated with the male.

Reed (1967) observed that, though gilts were apparently of an age and weight conducive to sexual maturity, they did not reach puberty in the absence of a boar. The present results show that in the absence of a boar just over half the gilts $(58 \%)$ reached puberty over the experimental period. When a boar was introduced, a larger number of animals reached puberty, and the mean pubertal age was reduced.

Little is known about the involvement of the male in female maturation. In mice, introduction of the male to prepubertal females has been shown to hasten sexual maturation (Vandenbergh, 1967). Both vaginal opening and commencement of cycling occurred earlier in mice which had a male present than in those isolated from a male. More recently, it has been shown that the odour of the male is sufficient to induce this effect (Vandenbergh, 1969).

Introduction of the male at 190 days of age (Group D), a time approximating the mean pubertal age within the herd, resulted in a marked synchrony in the attainment of puberty. This result agreed with previous observations (Brooks \& Cole, 1969). An even greater degree of synchrony was obtained in Group G, where the treatment was designed to induce puberty as soon as possible by rotation of the boars.

In both Groups $C$ and $D$, one animal reached puberty approximately 3 weeks after the introduction of the boar. An explanation of this may be that these two animals experienced a 'silent heat' (i.e. ovulation without psychic oestrus) following the introduction of the male, and only showed psychic heat at the subsequent oestrus. However, prepubertal silent cycles in the pig have not been reported elsewhere.

It is clear from the results obtained in Group $\mathrm{C}$ that puberty in the gilt may be stimulated as early as 165 days of age. It might be expected, therefore, that the gilts in Group B would show a similar pattern in the occurrence of puberty, as they also had contact with the boar from 165 days of age, but this did not occur. The Group-B gilts had contact with only one boar throughout the experiment, while those in Group $\mathbf{C}$ were exposed to a number of different boars. However, an additional difference was accidentally confounded with the number of boars used in each group. Due to an oversight, one of the boars used to test Group B for the first 2 days of the experiment (found to be unsuitable because of his size), was housed in an adjacent yard of dry sows, separated from the gilts only by a mesh-covered gate. This boar remained in the adjacent yard until the 20th day of the experiment by which time all but one of the gilts in Group $\mathrm{G}$ had reached puberty. The gilts in Group $\mathrm{C}$ thus had aural, visual and olfactory contact with a boar continuously over the first 20 days of the experiment whilst the Group B gilts had contact with a boar for only $30 \mathrm{~min} /$ day. Experiments are planned to determine whether the number of boars with which the gilts have contact or the continuity of contact provides the stimulus for sexual maturation.

In conclusion, it may be said that puberty was attained at an earlier age by gilts having contact with a boar than by those kept in the absence of a boar. Considerable synchrony in the attainment of puberty was obtained at 165 and 190 days. 


\section{AGKNOWLEDGMENT}

This work was carried out while one of us (P.H.B.) was receiving a grant from the Meat and Livestock Commission.

\section{REFERENCES}

BRooks, P. H. \& CoLE, D. J. A. (I969) The effect of boar presence on the age at puberty of gilts. Rep. Sch. Agric. Univ. Nott. (1968-69), p. 73.

RRED, H. G. D. (1967) Observations on oestrus, ovulation and fertility in the domestic pig. Ph.D. thesis, University of London.

Sumption, L. J., Rempel, N. E. \& Winters, L. M. (1961) The evolution of a new breed of swine. The Minnesota No. 3. J. Hered. 52, 265.

TAssell, R. (1967) The effects of diet on reproduction in pigs, sheep and cattle. I. Plane of nutrition in pigs. Br. vet. F. 123, 76.

Thibault, C., Courot, M., Martinet, L., Mauleon, P., du Mesnil du Buisson, F., Ortavant, R., Pelletier, J. \& Signoret, J. P. (1966) Regulation of breeding season and estrous cycles by light and external stimuli in some mammals. F. Anim. Sci. 25, (Suppl.), 119.

VANDENBERGH, J. G. (1967) Effect of the presence of a male on the sexual maturation of female mice. Endocrinology, 81, 345.

VANDENBergh, J. G. (1969) Male odour accelerates female sexual maturation in mice. Endocrinology, 84, 658. 